\title{
Evaluation of the Quality of Health Service Providers: The Iranian People Perspective 2014
}

\author{
Saeed Asefzadeh ${ }^{1}$, Soheyla Gholami ${ }^{2}$, Roya Rajaee ${ }^{3}$, Marziye Najafi ${ }^{3}$, Mehran Alijanzadeh ${ }^{4}$
}

${ }^{1} \mathrm{Ph} . \mathrm{D}$. of Health Care Management, Professor, Social Determinants of Health Research Center, Qazvin University of Medical Sciences, Qazvin, Iran

${ }^{2}$ M.Sc. of Health Care Management, Health Information Management Research Center, Hormozgan University of Medical Sciences, Bandar Abbas, Iran

${ }^{3}$ M.Sc. of Health Care Management, School of Public Health, Shahid Beheshti University of Medical Sciences, Tehran, Iran

${ }^{4}$ Ph.D. Student of Health Care Management, Social Determinants of Health Research Center, Qazvin University of Medical Sciences, Qazvin, Iran

\section{Type of article: Original}

\begin{abstract}
Introduction: Quality is the center of attention in all service providing organizations that are effective in promoting satisfaction of patients who are referred to medical centers. The aim of this study was to investigate the quality of health service providers in a case study of Qazvin, Iran, in 2014.

Methods: This descriptive study was conducted on 1,002 people who were residents of Qazvin Province (Iran) in 2014. The people were selected randomly from the population of the study area. The main variables studied were education, perceptions, expectations, and gaps in service quality. The data collection tool was the standard Servequal questionnaire. To determine the reliability of the research tool, we used Cronbach's Alpha coefficient and the test-retest method. Statistical analyses were conducted using SPSS and the ANOVA test.

Results: The mean age of people included in the study was $32 \pm 9.9$ years, and the average waiting time to receive services was $73 \pm 47$ minutes. Hospitals and doctors' offices had the highest quality gap of $-1.420 \pm 0.82$ and $-1.01 \pm 0.75$, respectively. The service quality gaps in medical centers, health providers of rural area, and health providers of urban area were $-0.883 \pm 0.67,-0.882 \pm 0.83$, and $-0.804 \pm 0.62$, respectively. There was a significant relationship between peoples' perceptions and expectations concerning the quality of health services and their educational levels.

Conclusion: The higher gaps in quality in hospitals and in doctors' offices require more attention. Managers and policy makers should consider developing and implementing plans to reduce these gaps in quality and to promote better health services in these two sectors.

Keywords: quality of services; service providing centers; health system
\end{abstract}

\section{Introduction}

In this century, new changes have resulted in rapid development of service-providing sectors, especially in the health sector (1). Services provided in different parts of society are considered as the heart of value-creation in the economy (2). Today, quality of services, especially in institutes with high volume of customers, including financial and care services, has found a great importance in such a way that it could be considered as an essential strategy to achieve the intended results in a competitive market (3). Quality has been converted into a big challenge to meet expectations of service receivers and their satisfaction (4). The problem of lack of quality in providing services occurs in organizations that do not focus on identifying and meeting customers' needs and demands. Lack of direct relation of organizations with customers finally will result in improper performance and lack of accountability to customers' expectations (5). Evaluating the quality of health services is a prominent scale to measure the amount of

\section{Corresponding author:}

Mehran Alijanzadeh, Social Determinants of Health Research Center, Qazvin University of Medical Sciences, Qazvin, Iran. Tel: +98.2833239259, Fax: +98.2833337006, Email: Mehranalijanzadeh@gmail.com

Received: October 16, 2015, Accepted: December 20, 2015, Published: March 2016

iThenticate screening: December 20, 2015, English editing: January 28, 2016, Quality control: March 05, 2016

(C) 2016 The Authors. This is an open access article under the terms of the Creative Commons Attribution-NonCommercialNoDerivs License, which permits use and distribution in any medium, provided the original work is properly cited, the use is non-commercial and no modifications or adaptations are made. 
realization of health and medical organizations (6). It should be noted that customers' satisfaction is obtained when organizations that provide health services, such as hospitals, medical centers, and clinics, pay attention to customers' expectations as well as their needs and implement required plans to meet customers' expectations (7). In today's competitive market, promotions are transferred to the society directly by patients or their families, and this issue is very important for medical organizations' providing positive experiences for patients and their families and positive perceptions of patients for services received are very important for service-providing organizations (8). The quality of health services generally is recognized as satisfaction of the patients who are referred to medical centers, which have a direct effect on quality and the customers' satisfaction. Therefore, most medical organizations seek to promote the quality of services to ensure that customers are satisfied with the services they receive (9). Patients who receive health services are regarded as the main beneficiaries of health system. Therefore, providing health care according to patients' preferences, expectations, and demands could promote the quality of hospital services (10, 11).

Expectations are one of the main determinants of customer evaluation of the quality of services, and the main step in providing quality services is accurate identification of customers' expectations. In fact, responding to patients' expectations is considered as one of the current challenges of the health system, and, in spite of its importance, the identification of patients' needs and demands has been neglected (12). Customers' perception is the key factor in their judgment of the quality of services. Customers compare their observations of the process of providing services with their expectations of those services, and they judge the quality of the services they receive based on the difference between their expectations and what they actually received. Therefore, a quality control strategy is required to reduce these gaps (13). The Servequal model is one of the most prominent tools to measure customers' expectations and perceptions. It is a diagnostic method for introducing weak and strong points of the quality of organizations' services (14). It measures the following five main dimensions of the quality of services:

1) Tangible aspects of service: physical facilities, equipment, appearance of personnel

2) Reliability of service provider: performing committed function accurately and reliably

3) Responsiveness of service provider: tendency toward helping and responding to customers' needs

4) Assurance provided by service provider: ability of personnel to induce trust and reliability

5) Empathy of service provider with customers: personal attention to customers (15).

This model has been used in many studies. In their study, Safi et al. concluded that quality gaps existed in terms of all five dimensions of the quality of health services in the medical centers north of Tehran. The lowest gap, i.e., 0.68, was in empathy, and the highest gap, i.e., -0.88 , was related to physical aspect of services (16). In the study by Alidoosti on the rural society of Shahr-e-Kord, the results suggested that health services provided in health providers of rural area are far from favorable, and $37 \%$ of the people in the study were weakly satisfied with the services provided (17). In a study of private hospitals in Malaysia, the findings showed that there was a significant gap between customers' perceptions and expectations of provided services that required basic interventions in these hospitals to reduce the gap of service quality (18). In the study by Padma et al. in the hospitals of India, patients were regarded as main concern of health service providers and hospitals paid special attention to patients' perceptions to promote the quality of services (19). Various studies have been conducted all around the world on the quality of health services. In studies conducted by Purcărea (20), John (21), Chakravarty (22), Zarei (23), NekoeiMoghadam (24), Li (25), Abedi (26), Xu (27), and Handayani (28), it was specified that there is a negative gap between perceptions and expectations of customers concerning the quality of provided services in health care providing units. It was believed that the need to promote quality of services and paying more attention to individuals in the society were the critical factors for the organizations. Garrard and Lin, in their studies, evaluated Servequal as a proper instrument to measure quality of services and stated that this instrument should be used to identify the gap between perceptions and expectations $(14,29)$. A study conducted in Qazvin Province, Iran, showed that there was a gap in the quality of health services in this Province. However, in this study, the gap distribution was not clear between service providers (30). With regard to the gap in quality of services in Qazvin Province (30) and the lack of studies conducted to measure the quality of health services in Qazvin City, the topic of this study in comprehensive health plans of Qazvin province and unified consensus of health exports of Qazvin to conduct a study on determination of the study of health services among providers was the main reason to conduct this study. In addition, assuring health services is very important for the health system and people, since they are very critical. Evaluating the quality of these services through people's perceptions and expectations is a good instrument. Therefore, the aim of this study was to investigate the quality of health-providing services according to residents of Qazvin Province in 2014. 


\section{Material and Methods}

This descriptive study was conducted with residents of Qazvin Province, Iran, in 2014. A samples size of 400 subjects was selected using the sample size formula and considering the maximum possibility of higher expectations of people compared to their perceptions, $\mathrm{p}=0.50$ and error coefficient of $5 \%$. By considering cluster effect 2 , sample size was considered to be 800 subjects. However, 1,002 subjects were studied for more accuracy. Due to the rural population of $25 \%$ relative to urban population in Qazvin, 253 rural and 749 urban samples were selected. Cluster sampling was used and samples were selected randomly from the urban population of Qazvin province. The counties of Qazvin, Takestan, Abyek, Booyinzahra, Avaj, and Alborz were investigated. The samples selected from Qazvin, Abyek, Avaj, Alborz, Boein Zahra, and Takestan totaled 403, 51, 38, 121, 44, and 92, respectively. The difference between the numbers of urban and rural samples was because of their population ratio with the cities. In addition, among the rural population of Abyeh, Avaj, Alborz, Boein Zahra, Takestan and Qazvin villages, 24, 16, $21,56,44$ and 82 samples were investigated respectively.

The standard Servequal questionnaire was used to collect data. This questionnaire included two sections: background variables (education, age, place of receiving services, waiting time to receive services) and main questions on five dimensions of service quality (physical, reliability, responsiveness, assurance, and empathy) in perceptions and expectations parts. The questionnaire consisted of 22 questions. There were four questions each in the physical, reliability, and responsiveness fields and five questions in the assurance and empathy fields. Quality of services was calculated using a 5-point Likert scale, ranging from strongly agree to strongly disagree. To determine the quality gap, scoring of customers to present situation (perceptions) of quality of health services provided was compared with their scoring to desirable status (expectations) of quality of health services. If the resulting score were positive, it showed that services provided were higher than peoples' expectations and in the case of being negative, it stated that health services provided did not meet peoples' expectations, and a quality gap exists. Zero score shows the lack of a quality gap, which demonstrates that health services provided are in line with peoples' expectations. The place of receiving services was shown as an option in the questionnaire, with six answers, including hospital, clinic, medical center, doctors' office, health providers of urban area, and health providers of rural area. In addition, the last place of referring to receive services was regarded as the option to be selected. The validity of the questionnaire was approved by Zarei and Nekoei-Moghadam in Iran $(23,24)$. Research tools were selected based on Cronbach's alpha score of 0.91 and test-retest method of 0.83 for reliability. Data were collected by going to peoples' houses in cities and villages and asking questions about the quality of units and health service providers in Qazvin Province. First, an explanatory workshop was held for interviewers, and its goal was to have experienced local forces of each area collect the data.

The Ethics Committee of Qazvin University of Medical Sciences approved this study with ID number of 8346. The importance of the study was explained to the participants by interviewers, and the participants were assured that the information they provided would be confidential. A consent form for participating in the study was completed by each subject. The data were analyzed using SPSS 21.00 and the ANOVA test.

\section{Results}

The mean age of the subjects was $32 \pm 9.9$, and the average waiting time to receive services was $73 \pm 47$ minutes. The frequency distribution of the education of the people in the study was $6 \%$ illiterate, $34 \%$ junior diploma $30 \%$ high school diploma, 10\% associate diploma, 18\% Bachelor's degree, and 2\% Master's degree and higher. The lowest perceptions of the quality of health service providers were related to hospitals, with an average of 3.26, followed by doctors' offices at 3.51. In addition, the highest perceptions of the quality of health service providing centers was related to health providers of urban area at 3.79 and medical centers at 3.70 (Table 1). The least expectations of people concerning the quality of service providers were related to clinics at 4.49 , and their highest expectations were related to hospitals at 4.68 . Respectively, the highest quality gap in health services was related to hospitals and doctors' offices with the values of -1.42 and -1.01 , respectively, and the lowest gap was related to health providers of urban area and health providers of rural area with the values of -0.80 and -0.88 , respectively (Table 1). The highest perception of 3.68 was related to junior diploma and the highest expectation of 4.69 was related to Master's degree. Furthermore, the lowest perception and expectations values of 3.30 and 4.48 were related to those who held Associate's diplomas (Table 2). There was a significant relationship between perceptions $(\mathrm{p}=$ $0.000)$, expectations $(p=0.01)$, and quality gap of health services $(p=0.000)$ with the health service provider. There was a significant relationship between people's perceptions and education $(p=0.000)$. In addition, there was a significant relationship between peoples' expectations and education. However, no significant relationship was observed between quality gap of health services and education $(p=0.2)$ (Table 3$)$. 
Table 1. Mean and standard deviation of perceptions and expectations of Qazvin residents of the quality of health services provided in health service providing centers in $2014(\mathrm{n}=1002)$

\begin{tabular}{|l|l|l|l|l|}
\hline Variables & Location of services received & $\mathrm{n}$ & Mean & SD \\
\hline \multirow{4}{*}{$\begin{array}{l}\text { People's perceptions of } \\
\text { service quality }\end{array}$} & Hospital & 228 & 3.268 & 0.808 \\
\cline { 2 - 5 } & Clinic & 149 & 3.501 & 0.574 \\
\cline { 2 - 5 } & Medical center & 259 & 3.706 & 0.641 \\
\cline { 2 - 5 } & Doctors' office & 211 & 3.519 & 0.714 \\
\cline { 2 - 5 } & health providers of urban area & 103 & 3.796 & 0.589 \\
\cline { 2 - 5 } & health providers of rural area & 50 & 3.682 & 0.665 \\
\hline \multirow{5}{*}{$\begin{array}{l}\text { People's expectations of } \\
\text { service quality }\end{array}$} & Hospital & 228 & 4.689 & 0.402 \\
\cline { 2 - 5 } & Clinic & 149 & 4.497 & 0.618 \\
\cline { 2 - 5 } & Medical center & 259 & 4.590 & 0.492 \\
\cline { 2 - 5 } & Doctors' office & 211 & 4.535 & 0.533 \\
\cline { 2 - 5 } & health providers of urban area & 103 & 4.601 & 0.535 \\
\cline { 2 - 5 } & health providers of rural area & 50 & 4.565 & 0.633 \\
\hline \multirow{5}{*}{ Service quality gap } & Hospital & 228 & -1.420 & 0.828 \\
\cline { 2 - 5 } & Clinic & 259 & -0.991 & 0.735 \\
\cline { 2 - 5 } & Medical center & -0.883 & 0.674 \\
\cline { 2 - 5 } & Doctors' office & -1.016 & 0.751 \\
\cline { 2 - 5 } & health providers of urban area & 103 & -0.804 & 0.624 \\
\cline { 2 - 5 } & health providers of rural area & 50 & -0.882 & 0.831 \\
\hline
\end{tabular}

Table 2: Mean and standard deviation of perceptions and expectations of Qazvin residents of the quality of health services provided in health service providing centers in different educational levels in this Province in 2014 ( $\mathrm{n}=$ 1002)

\begin{tabular}{|l|l|l|l|l|}
\hline Variables & Level of education & $\mathrm{n}$ & Mean & SD \\
\hline \multirow{4}{*}{$\begin{array}{l}\text { public's perceptions of } \\
\text { service quality }\end{array}$} & Illiterate & 63 & 3.581 & 0.707 \\
\cline { 2 - 5 } & Junior diploma & 344 & 3.686 & 0.673 \\
\cline { 2 - 5 } & High school diploma & 297 & 3.475 & 0.669 \\
\cline { 2 - 5 } & Associate degree & 104 & 3.309 & 0.739 \\
\cline { 2 - 5 } & Bachelor's degree & 178 & 3.509 & 0.749 \\
\cline { 2 - 5 } & Master's degree & 16 & 3.539 & 0.845 \\
\hline \multirow{4}{*}{$\begin{array}{l}\text { Public's expectations of } \\
\text { service quality }\end{array}$} & Illiterate & 63 & 4.596 & 0.550 \\
\cline { 2 - 5 } & Junior diploma & 297 & 4.671 & 0.449 \\
\cline { 2 - 5 } & High school diploma & 104 & 4.565 & 0.532 \\
\cline { 2 - 5 } & Associate degree & 178 & 4.509 & 0.552 \\
\cline { 2 - 5 } & Bachelor's degree & 16 & 4.696 & 0.425 \\
\cline { 2 - 5 } & Master's degree & & & \\
\hline
\end{tabular}

Table 3: Relationship between people's perceptions and expectations of residents of Qazvin Province with the place of receiving health services and different educational levels in this Province in $2014(\mathrm{n}=1002)$

\begin{tabular}{|l|l|l|l|}
\hline Variables & F statistics (ANOVA test) & p-value \\
\hline \multirow{2}{*}{$\begin{array}{l}\text { Service quality and place of } \\
\text { receiving services }\end{array}$} & People's perceptions & 11.49 & 0.000 \\
\cline { 2 - 4 } & People's expectations & 2.16 & 0.01 \\
\cline { 2 - 4 } & Service gap & 14.33 & 0.000 \\
\hline \multirow{2}{*}{$\begin{array}{l}\text { Service quality and level of } \\
\text { education }\end{array}$} & People's perceptions & 5.91 & 0.000 \\
\cline { 2 - 4 } & People's expectations & 3.78 & 0.002 \\
\cline { 2 - 4 } & Service gap & 1.39 & 0.223 \\
\hline
\end{tabular}

\section{Discussion}

Study of quality gap in all health service providers and comparing them with each other was one of the main issues in this study that has never been found before in other studies and was considered as its strong point. In current study, the highest quality gap of -1.42 in health services was related to hospitals and the lowest quality gap of -0.80 
was related to health service providers of health providers of urban area. In a study conducted by Jenaabadi et al. in hospitals of Zahedan, there was a significant difference in all dimensions of quality between average of perceptions and expectations score. Quality gaps in tangibles, reliability, responsiveness, assurance, and empathy were - 0.690 , $0.685,0.795,-0.755$, and -0.840 , respectively (31). In a study conducted of the hospitals of Arak, the quality gap of health services was reported to be -1.20 (32), and that complied with the findings of this study. It appears that Arak and Qazvin are very similar in terms of results because both are industrial cities.

In a study by Mohammadi on a medical center in Zanjan, negative gaps were observed in all five quality aspects. In Mohammadi's study, the averages of people's perceptions and expectations for the quality of health services were 3.04 and 4.26, respectively, and the quality gap was -1.22 (33), which complied with the current study in terms of quality gap. The results of a study conducted in Khorramabad showed that the quality gap of health services was 0.69 (34), which complied with our findings. The results of a study conducted by Ghobadi on doctors' offices of Ardebil revealed a quality gap of -0.65 in health services (35). Quality gap in doctors' offices was higher in Qazvin Province than in Ardebil, which requires reforms and fundamental policy making to reduce this gap. The results of a study conducted by Noronesa in Fasa revealed that doctors' offices need fundamental reforms in terms of meeting patients' expectations to promote quality of health services (36). In studies conducted by Sahebzadeh in Isfahan (37) and Azizi in Darab (38), customers' satisfaction with health service providers was not favorable, and that requires policies and plans to promote present situation and move toward favorable status. In studies by Butt in Malaysia (39), Rohini in India (40), Bakar in Turkey (41), and Arasli in Cyprus (42), there was a negative gap between patients' perceptions and expectations in all dimensions of quality of services. In spite of different values of this gap in various studies, it is clear that there is a gap in providing health services all around the world, and fundamental interventions are required to reduce this gap in services. In a study by Gorji (43) and Mohammadnia (44), negative gaps were observed in quality of health services between customers' perceptions and expectations. Contrary to all studies conducted in Iran, the research society of which was limited, in this study people were investigated in person in all areas of Qazvin Province by referring to people's houses, which is considered as one of the strong points of this study. In addition, in this study all health service providers, including hospitals, clinics, medical centers, health providers of urban area, doctors' offices, and health providers of rural area were compared that have never considered before in other studies. Studies by Taner (45), Schröder (46), and Suki (47) estimated people's perceptions to be lower than their expectations in terms of quality of health services, which demonstrated a quality gap and lack of meeting expectations of people who were referred to receive health services. In a study conducted in Peru, a relationship was found between people's satisfaction with health services and their education and type of services received (48). In a study conducted in Indonesia, the results showed that trained staff and experienced physicians promote the quality of services and increase satisfaction (49). In a study conducted by Al-Borie in Saudi Arabia, a significant relationship was found between education and perceptions and satisfaction from the quality of health services (50) that complied with results of current study.

Of limitations of this study were scattered counties in Qazvin province. Therefore, it was attempted to use local experts to collect data and investigate all regions as far as possible.

\section{Conclusions}

The results of this study showed that there was a service quality gap in all health service providers; however, it was higher in hospitals and doctors' offices. Since providing human and material resources of health system always involves problems, the practical importance of these findings lies in the fact that weak points could be emphasized more to reduce quality gap in services of hospitals and doctors' offices. To reduce quality gap in services, it is suggested that authorities consider customers' complaints and deal with them, make essential services available 24 hours a day, promote motivation of staff and physicians to pay more attention to customers, and the staff and physicians should consider the requests and reasonable needs of customers. Conducting a complementary study on quality gap of services between state and private sectors in Qazvin Province with descriptive methodology could be an appropriate path for future studies in this field.

\section{Acknowledgments:}

The authors of this study appreciate the Head of Research Centre of Social Determinants of Health and the Research and Health Deputy at the Qazvin University of Medical Sciences, as well as all experts of urban and rural medical centers of Qazvin Province, health providers of rural area, and all who assisted us in conducting this project (ID 8346). 


\section{Conflict of Interest:}

There is no conflict of interest to be declared.

\section{Authors' contributions:}

All authors contributed to this project and article equally. All authors read and approved the final manuscript.

\section{References}

1) Sunol R, Wagner C, Arah OA, Kristensen S, Pfaff H, Klazinga N. Implementation of Departmental Quality Strategies Is Positively Associated with Clinical Practice: Results of a Multicenter Study in 73 Hospitals in 7 European Countries. PLoS One. 2015; 10(11): 141. doi: 10.1371/journal.pone.0141157, PMID: 26588842, PMCID: PMC4654525.

2) Sohrabi R, bakhtiyari H. Quality assessment tool for the performance evaluation and analysis of evaluation models of service quality (SERVQUAL). Scientific Convention Center, Third National Conference on Management Practice 2007: 3(6): 1 - 18.

3) Prattana P, Nattapan B, Patchaya M. Health Care Service Quality: Case Example of a Hospital with Lean Implementation. POMS 23 rd Annual Conference, Chicago, Illinois, U.S.A. April 20 to April 23, 2012.

4) LariSemnani B, Mohebbi Far R, Shalipoor E, Mohseni M. Using creative problem solving (TRIZ) in improving the quality of hospital services. Glob J Health Sci. 2014; 7(1): 88-97. doi: 10.5539/gjhs.v7n1p88, PMID: 25560360.

5) Gholami A, Noori A, Khojastepoor M, Asgari M, Sajadi H. Gaps in the quality of primary health care services provided by health centers - Care Nishapur city. Scientific Journal of shahed university. 2011; 18(92): 1 - 11.

6) Zhao Z, Cheng J, Xu S. A quality assessment index framework for public health services: a Delphi study. Public health. 2015; 129: 43-51. doi: 10.1016/j.puhe.2014.10.016, PMID: 25553920.

7) Khamis K, Njau B. Patients' level of satisfaction on quality of health care at Mwananyamala hospital in Dar es Salaam, Tanzania. BMC Health Serv Res. 2014; 18(14): 400. doi: 10.1186/1472-6963-14-400, PMID: 25230739, PMCID: PMC4263110.

8) Bush VD, Bush AJ, Clark P, Bush RP. Girl power and word-of-Mouth Behavior in the flourishing sports market. Journal of Consumer Marketing. 2005; 22(5): 257-64. doi: 10.1108/07363760510611680.

9) Gutierrez J, Navarro J, Carrion A. Linking unlearning with quality of health service through knowledge. J BUS RES .2015; 68: 815-22. doi: 10.1016/j.jbusres.2014.11.034.

10) Speight J. Assessing patient satisfaction: concepts, applications, and measurement. Value in Health. 2005; 8: 36-8. doi: 10.1111/j.1524-4733.2005.00071.x, PMID: 16336490.

11) Pakdil F, Harwood TN. Patient satisfaction in a preoperative assessment clinic: An analysis using SERVQUAL dimensions. Total Quality Management \& Business Excellence. 2005; 16(1): 15-30. doi: $10.1080 / 1478336042000255622$.

12) Dormohammadi T, Asghari F, Rashidian A. What Do Patients Expect from Their Physicians? Iran J Public Health. 2010; 39(1): 70-7. PMID: 23112992, PMCID: PMC3468967.

13) Strawderman L. Human factors consideration in quality of service metrics for health care delivery, $\mathrm{PhD}$ Thesis in Industrial Engineering, The Graduate School College of Engineering, The Pennsylvania State University.2005; 3(9): 19-55.

14) Garrard F, Narayan H. Assessing obstetric patient experience: a SERVQUAL questionnaire. Int J Health Care Qual Assur. 2013; 26(7): 582-92. doi: 10.1108/JJHCQA-08-2011-0049, PMID: 24167918.

15) Huang Y, Li S. Understanding quality perception gaps among executives, frontline employees, and patients: the outpatient services in Taiwan hospitals. Quality Management Health Care. 2010; 19(2): 17384. doi: 10.1097/QMH.0b013e3181db647f, PMID: 20351544.

16) Safi MH, Fereydounfar AA, Arshi SH. Quality of Primary Health Services in the Clinics of Shomal Health Center of Tehran. Community Health. 2014; 1(1): 54-61.

17) Alidoosti M, Tavassoli E, Delaram M, Najimi A, Sharifirad G. The relationship between satisfaction and knowledge about family-doctor program in Shahr-e-Kord. Zahedan J Res Med Sci .2011; 13(6): 36-9.

18) Al-Momani MM. Gap Analysis between Perceptions and Expectations of Medical-Surgical Patients in a Public Hospital in Saudi Arabia. Med Princ Pract. 2016; 25(1): 79-84. doi: 10.1159/000441000, PMID: 26501371. 
19) Padma P, Rajendran C, Lokachari PS. Service quality and its impact on customer satisfaction in Indian hospitals: Perspectives of patients and their attendants. Benchmark Int J. 2010; 17(6): 807-41. doi: 10.1108/14635771011089746.

20) Purcărea VL, Gheorghe IR, Petrescu CM. The Assessment of Perceived Service Quality of Public Health Care Services in Romania Using the SERVQUAL Scale. Procedia Economics and Finance. 2013; 6: 57385. doi: 10.1016/S2212-5671(13)00175-5.

21) John J, Yatim FM, Mani SA. Measuring service quality of public dental health care facilities in Kelantan, Malaysia. Asia Pac J Public Health. 2011; 23(5): 742-53. doi: 10.1177/1010539509357341, PMID: 20460281.

22) Chakravarty A. Evaluation of service quality of hospital outpatient department services. Medical Journal Armed Forces India. 2011; 67(3): 221-4. doi: 10.1016/S0377-1237(11)60045-2.

23) Zarei A, Arab M, Froushani AR, Rashidian A, Ghazi Tabatabaei SM. Service quality of private hospitals: the Iranian patients' perspective. BMC Health Serv Res. 2012; 2(12): 31. PMID: 22299830.

24) Nekoei-Moghadam M, Amiresmaili M. Hospital services quality assessment: Hospitals of Kerman University of Medical Sciences, as a tangible example of a developing country. Int J Health Care Qual Assur. 2011; 24(1): 57-66. doi: 10.1108/09526861111098247, PMID: 21456498.

25) Li M, Lowrie D, Huang C, Lu X, Zhu Y, Wu X. Evaluating patients' perception of service. quality at hospitals in nine Chinese cities by use of the Servqual scale. Asian Pac J Trop Biomed. 2015; 5(6): 497504. doi: 10.1016/j.apjtb.2015.02.003.

26) Abedi G, Rostami F, Ziaee M, Siamian H, Nadi A. Patient's Perception and Expectations of the Quality of Outpatient Services of Imam Khomeini Hospital in Sari City. Mater Sociomed. 2015; 27(4): 272-5. PMID: 26543422.

27) Xu Y, Liu Y, Shu T, Yang W, Liang M. Variations in the Quality of Care at Large Public Hospitals in Beijing, China: A Condition-Based Outcome Approach. PLoS One. 2015; 10(10): e0138948. doi: 10.1186/1477-7525-7-63, PMID: 19591682, PMCID: PMC2716305.

28) Handayani P, Hidayanto A, Indahati P, Sandhyaduhita K, Ayuningtyas D. Strategic hospital services quality analysis in Indonesia. Expert Systems with Applications. 2015; 42(6): 3067-78. doi: 10.1016/j.eswa.2014.11.065.

29) Lin D-J, Sheu I-C, Pai J-Y, Bair A, Hung C-Y, Yeh Y-H, et al. Measuring patient's expectation and the perception of quality in LASIK services. Health Qual Life Outcomes. 2009; 7: 63-8. doi: 10.1186/14777525-7-63, PMID: 19591682, PMCID: PMC2716305.

30) Alijanzadeh M, Asefzadeh S, khoshtarkib H, Ghamari F, Alijanzadeh M. The Perceptions and Expectations Survey of the People about Quality Health Services in Qazvin Province. Health Inf Manage. 2015; 12(5): $600-10$.

31) Jenaabadi H, Abili Kh, Nastizayi N, Yaghubi N .Between patients' perceptions and expectations of service quality in Zahedan's centers with SERVQUAL model. Payesh Journal. 2011; 10(4): 449-57.

32) Hekmatpo D, Sorani M, Farazi A. A survey on the quality of medical services in teaching hospitals of Arak University of Medical Sciences with SERVQUL model in Arak, 2010. Arak Medical University Journal. 2012; 15(66): 1-9.

33) Mohammadi A, Shoghli AR. Survey on Quality of Primary Health Cares in Zanjan District Health Centers. Journal of zanjan university of medical sciences.2009; 16(65): 89-100.

34) tarrahi M, Hamouzadeh P, Bijanvand M, Lashgarara B. The quality of health care services provided in health care centers of Khorramabad using SERVQUAL model in 2010. Yafteh. 2012; 14(1): 13-21.

35) Ghobadi H, Mehrnoush N, Hamidkholgh G. Measuring the Quality of Services Provided for Outpatients in Kowsar Clinic in Ardebil City Based on the SERVQUAL Model. Journal of Ardabil University of Medical Sciences. 2014; 14(4): 379-87.

36) Noronesa R, Rezaian S, Moradi S. Patient satisfaction with the services of general practitioners: a cross sectional study. Journal of Medical Ethic. 2012; 6(22): 15-23.

37) Sahebzadeh M, Rahimyan M. A Study of the satisfaction rate of elderly patients in general hospitals affiliated with the Isfahan University of Medical Sciences in 2009. Teb Va Tazkieh. 2010; 20(4): 46-58.

38) Azizi J, Karimyar Jahromi M, Hojat M. Assessment of Darab County Villagers' Satisfaction with Family Doctor Functions from Different Aspects. Journal of Fasa University of Medical Sciences. 2012; 2(3): 1938.

39) Butt MM, de Run EC. Private healthcare quality: applying a SERVQUAL model. Int J Health Care Qual Assur. 2010; 23(7): 658-73. doi: 10.1108/09526861011071580, PMID: 21125961. 
40) Rohini R, Mahadevappa B. Service Quality in Bangalore Hospitals - an Empirical Study. Journal of Services Research. 2006; 6(1): 16-23.

41) Bakar C, Akgün HS, Al Assaf A. The role of expectations in patient assessments of hospital care: an example from a university hospital network, Turkey. Int J Health Care Qual Assur. 2008; 21(4): 343-55. PMID: 18785460 .

42) Arasli H, Ekiz EH, Katircioglu ST. Gearing service quality into public and private hospitals in small islands: empirical evidence from Cyprus. Int J Health Care Qual Assur. 2008; 21(1): 8-23. PMID: 18437935.

43) Gorji A, Akbari A, Sarkhosh S. Using the Service Quality Gap's Model (SERVQUAL) in Imam Khomeini Teaching Hospital. Health management. 2013; 51(16): 11-8.

44) Mohammadnia M, Delgoshaei Survey on Nursing Service Quality by SERVQUAL at Tehran Social Security Organization Hospitals. Hospital journal. 2012; 12(1): 63-72.

45) Taner T, Antony J. Comparing public and private hospital care service quality in Turkey. Int J Health Care Qual Assur Inc Leadersh Health Serv. 2006; 19(2-3):i-x. doi: 10.1108/13660750610664991, PMID: 16875104.

46) Schröder A, Ahlström G, Larsson BW. Patients' perceptions of the concept of the quality of care in the psychiatric setting: a phenomeno graphic study. J Clin Nurs. 2006; 15(1): 93-102. doi: 10.1111/j.13652702.2005.01241.x, PMID:16390528.

47) Suki NM, Lian JCC, Suki NM. Do patients' perceptions exceed their expectations in private healthcare settings? Int J Health Care Qual Assur. 2011; 24(1): 42-56. doi: 10.1108/09526861111098238, PMID: 21456497.

48) Sihuin-Tapia EY, Gómez-Quispe OE, Ibáñez-Quispe V. Satisfaction of hospitalized patients in a hospital in Apurimac, Peru. Rev Peru Med Exp Salud Publica. 2015; 32(2): 299-302. PMID: 26338391.

49) Cordero Tous N, Horcajadas Almansa Á, Bermúdez González GJ, Tous Zamora D. Perceived quality in hospitals of the Andalusia Healthcare System. The case of neurosurgery departments. Rev Calid Asist. 2014; 29(6): 311-9. PMID: 25534568.

50) Al-Borie HM, Damanhouri AM. Patients' satisfaction of service quality in Saudi hospitals: a SERVQUAL analysis. Int J Health Care Qual Assur. 2013; 26(1): 20-30. doi: 10.1108/09526861311288613, PMID: 23534103. 